\title{
WORKSHOP
}

\section{RATE MAKING AND SOCIETY'S SENSE OF FAIRNESS}

\author{
By G. W. DE Wit and J. van Eeghen \\ Nationale-Nederlanden N.V.-Research Department \\ P. O. Box 796, 3000 AT Rotterdam, Netherlands
}

\section{INTRODUCTION AND SUMMARY}

Actuaries have always been in search of ways to determine premiums which match the risks insured as closely as possible. They do this by differentiating between them on the basis of observable risk factors. In practice, many examples of such risk factors are being used: age and sex for life insurance; location, type of building etc. for fire insurance. Motor insurance is perhaps the most characteristic branch with respect to this phenomenon: in tariffs we find factors like weight, price or cylinder capacity of the car, age of the driver, area of residence, past claims experience (Bonus/Malus), annual mileage etc.

Outsiders may not always be very positive about such a refined premium differentiation. The basis of insurance, they say, should be solidarity among insureds; premium differentiation is basically opposed to this. Another statement heard in the field is: "Premium differentiation ultimately results in letting every individual pay his own claims, it is the end of insurance".

Much confusion arises during discussions about this subject, especially between actuaries and non-actuaries. We will therefore first give a mathematical definition of solidarity, (Section 2), followed by a brief description of certain trends in society which might bring insurers to deliberately drop certain risk factors from their tariffs in order to increase solidarity (Section 3). The consequences of doing so are examined and it is shown that increased solvency requirements will in the end prove to be ineffective. A possible solution is a voluntary transfer of premium between companies (Section 4). The situation is illustrated by an example of health insurance in the Netherlands, where proposals to arrive at such transfers are presently being discussed.

\section{FORMS OF SOLIDARITY}

If no insurance is purchased, the situation can be briefly summarized as follows:

\begin{tabular}{lcc}
\hline \hline & $\begin{array}{c}\text { Carried by } \\
\text { Insured }\end{array}$ & $\begin{array}{c}\text { Carried by } \\
\text { Insurer }\end{array}$ \\
\hline Risk & $\boldsymbol{X}$ & 0 \\
Expected risk & $E(X)$ & 0 \\
Variance of risk & $\operatorname{Var}(\boldsymbol{X})$ & 0 \\
\hline
\end{tabular}

where $X$ is the random variable representing the claims of a random insured. ASTIN BULLETIN Vol. 14, No. 2 
By the insurance transaction, the risk is transferred from the insured to the insurer. In exchange the insured pays a premium equal to $E(X)$, if we use the expected value premium principle and ignore loadings and estimation errors. The result of the transaction is:

\begin{tabular}{lcc}
\hline \hline & $\begin{array}{c}\text { Carried by } \\
\text { Insured }\end{array}$ & $\begin{array}{c}\text { Carried by } \\
\text { Insurer }\end{array}$ \\
\hline Risk & $E(X)$ & $X-E(X)$ \\
Expected risk & $E(X)$ & 0 \\
Variance of risk & 0 & $\operatorname{Var}(X)$ \\
\hline
\end{tabular}

It has been recognized however that risks are like leaves in a tree: similar, but never identical. We therefore say that the risk of an individual is characterized by a distribution $P_{\theta}$, where $\theta$ differs from one insured to another. $\theta$ is unobservable and is in turn looked upon as a realization of a random variable $\Theta$, whose distribution is characteristic for the market. Thus the risk process is divided into two parts: first the " $\Theta$-lottery" (which is the realization of $\Theta$ and can be viewed as an underwriting experiment: each time a risk is accepted a $\theta$ is drawn at random from the population $\Theta$ ); then the "claims lottery" ruled by the probability law $P_{\theta}$. Suppose for a moment that $\theta$ is observable and that the insurer fixes the premium after observing the outcome of the $\Theta$-lottery. If the outcome of $\Theta$ is $\theta$, the premium charged will be the conditional expectation $E(X \mid \Theta=\theta)$. The premium of an insured randomly drawn from the collective then becomes a random variable itself: $E(X \mid \Theta)$. This situation can be represented as follows:

\begin{tabular}{lcc}
\hline \hline & $\begin{array}{c}\text { Carried by } \\
\text { Insured }\end{array}$ & $\begin{array}{c}\text { Carried by } \\
\text { Insurer }\end{array}$ \\
\hline Risk & $E(X \mid \Theta)$ & $X-E(X \mid \Theta)$ \\
Expected risk & $E(X)$ & 0 \\
Variance of risk & $\operatorname{Var}\{E(X \mid \Theta)\}$ & $E\{\operatorname{Var}(X \mid \Theta)\}$ \\
\hline
\end{tabular}

While in the first example the insured transferred his full risk to the insurer ( $X$ is replaced by $E(X)$ ), he now keeps part of the risk for himself, for his premium $E(X \mid \Theta)$ is a random variable.

We may now define actual solidarity as the variance of the risk transferred to the insurer (i.e., shared among insureds). Full solidarity is achieved in the first example:

$$
S=\operatorname{Var}(X)
$$


In the second example the actual solidarity remains restricted to the "purely probabilistic" part of it:

$$
S_{p}=E\{\operatorname{Var}(X \mid \Theta)\} .
$$

The part of the variance which is caused by $\Theta$, the "risk solidarity", remains with the insured:

$$
S_{r}=\operatorname{Var}\{E(X \mid \Theta)\} .
$$

The subdivision is complete now, for it can easily be checked that

$$
S=S_{p}+S_{r}
$$

As we have said before, $\theta$ is unobservable; the probability distribution of an individual risk is never known. However, we do have some information on the differences in distribution of the risks in our portfolio by means of observable risk factors. These risk factors can be viewed as a (vector-valued) random variable $F$. Mathematically, every potential $F$ satisfies the following:

$$
\text { for all sets } A: \quad \operatorname{Pr}\{X \in A \mid \Theta, F\}=\operatorname{Pr}\{X \in A \mid \Theta\}
$$

i.e., the conditional distribution of the risk given $\Theta$ does not depend on $F$.

If each insured is charged a premium $E(X \mid F)^{*}$ (i.e., information on risk factors is taken into account in pricing), the result of the insurance transaction is as follows:

\begin{tabular}{lcc}
\hline \hline & $\begin{array}{c}\text { Carried by } \\
\text { Insured }\end{array}$ & $\begin{array}{c}\text { Carried by } \\
\text { Insurer }\end{array}$ \\
\hline Risk & $E(X \mid F)$ & $X-E(X \mid F)$ \\
Expected risk & $E(X)$ & 0 \\
Variance of risk & $\operatorname{Var}\{E(X \mid F)\}$ & $E\{\operatorname{Var}(X \mid F)\}$ \\
\hline
\end{tabular}

Now we can write:

$$
\operatorname{Var}(X \mid F)=E\left(X^{2} \mid F\right)-E^{2}(X \mid F)
$$

(because of (1))

$$
\begin{aligned}
& =E\left\{E\left(X^{2} \mid \Theta\right) \mid F\right\}-E^{2}\{E(X \mid \Theta) \mid F\} \\
& =E\{\operatorname{Var}(X \mid \Theta) \mid F\}+\operatorname{Var}\{E(X \mid \Theta) \mid F\}
\end{aligned}
$$

\footnotetext{
* We implicitely assume that a good estimate of $E(X \mid F)$ is available. For simplicity, we assume that $E(X \mid F)$ (like $E(X)$ ) is known. In actual practice however, the choice of $F$ is limited to those factors for which a good (small variance) estimate of $E(X \mid F)$ is available.
} 
Hence

$$
\begin{aligned}
E\{\operatorname{Var}(X \mid F)\} & =E\{\operatorname{Var}(X \mid \Theta)\}+E\{\operatorname{Var}[E(X \mid \Theta) \mid F]\} \\
& =\quad S_{p}+S_{u r}
\end{aligned}
$$

$S_{u r}$ can be interpreted as the part of risk solidarity $S_{r}$ that remains unknown after the information contained in $F$ has been taken into account. It may therefore be called the "unknown-risk solidarity".

Similarly, $\operatorname{Var}\{E(X \mid F)\}$ can be viewed as the part of $S_{r}$ that becomes known through $F$. It is therefore called the "known-risk solidarity", $S_{k r}$

Evidently we have:*

$$
S=S_{p}+S_{r}=S_{p}+S_{u r}+S_{k r}
$$

The result of the insurance transaction (with premiums equal to $E(X \mid F)$ ) can therefore be rewritten as:

\begin{tabular}{lcc}
\hline \hline & $\begin{array}{c}\text { Carried by } \\
\text { Insured }\end{array}$ & $\begin{array}{c}\text { Carried by } \\
\text { Insurer }\end{array}$ \\
\hline Risk & $E(X \mid F)$ & $X-E(X \mid F)$ \\
Expected risk & $E(X)$ & 0 \\
Variance of risk & $S_{k r}$ & $S_{p}+S_{u r}$ \\
\hline
\end{tabular}

The endeavours of the rate making actuary can now be represented as follows:

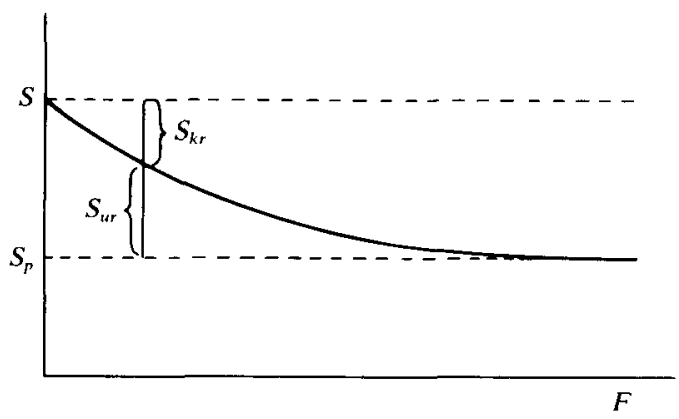

FIGURE 1. Solidarity shared among insureds.

* These relations hold only if premiums are based on the expected value of $X$ (conditionally or not to $\Theta$ or $F$ ). In social insurance however, premiums may not be related to the risk insured at all. Think e.g., of income related premiums or premiums which have to be paid in spite of the certainty one will never receive a benefit (women having to pay for a widow's pension under the Dutch social insurance). In such cases actual solidarity can be defined as

$$
E\left[E\left\{(X-P(F))^{2} \mid F\right\}\right]
$$

(where $P(F)$ is the premium payable) which may well exceed $S=\operatorname{Var}(X)$. 
As $F$ moves "towards full information about $\Theta$ " (i.e., towards the right in the above graph) - which is what the actuary tries to achieve-the unknown risk solidarity $S_{u r}$ will tend towards 0 , and the solidarity shared among insureds will remain restricted to $S_{p}$. If no $F$ is used for rate making purposes, i.e., $F$ is at the origin of the graph, then there will be full solidarity.

\section{SOCIETY'S SENSE OF FAIRNESS}

In the past, it used to be very difficult to discover risk factors both in a qualitative and in a quantitative sense. Solidarity was therefore-unavoidably-considerable. But recent developments have changed this situation:

- with the help of computers it has become possible to make thorough risk analyses, and consequently to arrive at further premium differentiation,

- the consumer's attitude towards tariffs became more critical. He requested more information and, if he was a good risk, objected to pay the same premium as the bad ones.

Both developments have their own special character. The first one shows that in recent years the actuary has been successful in his travel to the right of the $F$-axis of fig. 1 (see for instance DE Wit (1982) or van Eeghen, Greup and NiJssen (1983)). With the help of large data files and the possibility to analyse such data in detail, he is on his way to reduce actual solidarity to purely probabilistic solidarity $S_{p}$. This $S_{p}$ is the smallest possible value of the actual solidarity shared among insureds. It can be considered as a limit-situation in which $F$ contains all information about $\Theta$. BICHSEL (1983) has shown that an insurance system in which each insured is charged a premium equal to the expected value of future claims leads to the optimization of the total result of the economy. Along the same lines, one might argue that the minimization of solidarity through further refinements of tariffs, leads to the optimization of the total result of the economy as well.

The consumer's attitude is of a completely different nature. In the past, we believe he would be more inclined to simply accept the premium charged, but today things seem to be different. Premiums have increased a great deal, coverages have been extended and the risks of society have grown. Because of the relative level of premiums, the consumer has become more sensitive to price differences. Price sensitivity is probably also closely related to the general economic situation. In days of rapid economic growth and an ever increasing level of personal consumption, people will pay less attention to premium differences than in times of stagnation and budget squeezes. These developments tend to decrease total solidarity.

Nevertheless a changing attitude is starting to become apparent, caused by a critical review of today's society. It is this change that gives rise to the type of statements mentioned in the introduction. People start realizing that a certain restauration of solidarity might be desirable. For insurance, this seems to apply especially to those branches which are in the closest relation to people themselves. 
Therefore: healthy persons will be paying for the less healthy ones. And: should someone who works under circumstances which endanger his physical condition have to pay a higher premium in spite of the fact his work is of vital importance to the economy? The answer to such questions is often determined by the degree of influence a person has on his own risk. Should solidarity be extended to cover those people who harm their own health by their voluntarily chosen way of life? The answer to this question would generally be affirmative, but a non-smoker's discount, for instance, denies this form of solidarity. One might object against this form of solidarity, because it reduces one's own responsibility and has an anti-prevention character. It therefore seems justified to restrict solidarity to factors for which one is not personally responsible. Alternatively, the community can impose solidarity by safety rules (helmets for motorcyclists, safety belts in cars etc.)

But solidarity is not merely related to "personal" branches of insurance, but applies to more material fields also. Should someone who, for economic reasons, lives in a certain area pay a higher motor insurance premium, because of the higher traffic risks? The higher rent he has to pay in such an area may even be compensated by special subsidies. This brings us to a totally different aspect of solidarity. Should premiums be such that everyone can afford insurance? In the past, this question used to be relevant for social insurance only. The reasoning of private insurers was: if you cannot pay for insurance, don't buy it. But times have changed. Many types of insurance have become such common commodities, that they are being considered as basic needs and must therefore be affordable by everyone. If private insurers do not want to see their tasks taken over by social insurance they should keep this aspect in mind.

Where the foregoing considerations have a mainly social character, legal aspects may (or will) also be important, in the form of restrictions which preclude insurance companies from using certain risk factors, even if these factors can be proved to be statistically significant. We are thinking of:

- emancipation. It will no longer be allowed to distinguish between men and women for rate making purposes. For the European Community this rule will be laid down in a forthcoming directive;

- discrimination. Tariffs are not allowed to differentiate between racial groups.

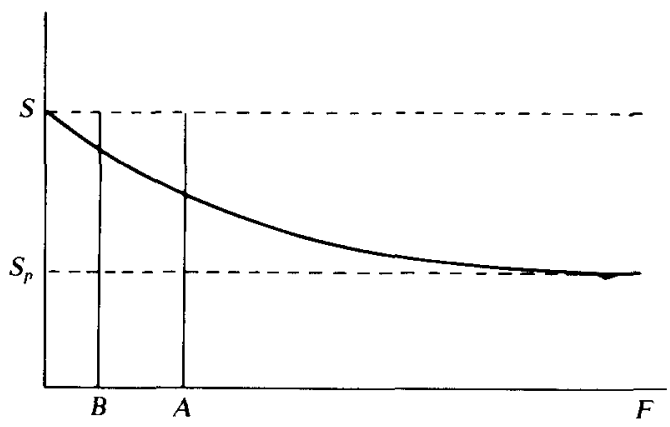

Figure 2 
What we are saying is that there may be reasons (mostly related to society's sense of fairness) for us not to use certain parts of the risk information available in our tariffs. Although we might be able to push premium differentiation to point $A$ in figure 2, we prefer to stick with situation $B$. In practice, the difference between $A$ and $B$ can be quite significant.

\section{CONSEQUENCES OF DELIBERATELY IGNORING RISK INFORMATION}

If it is decided that not all information available will be used for the rating structure, this policy should be adopted by all companies operating on the same market. It will be clear that, if with one company two different risks have to pay the same premium, while with another one the good risks pay a low premium and the bad risks a higher one, the former will attract relatively more bad risks and thus will incur a loss.* This implies that in a market where every company is free to fix its own rating structure (like the Dutch or the British ones) it will be less easy to respond to social pressure for "fairness" than in markets where rating structures are imposed by the authorities (like in Germany or Belgium).

But even in a regulated market there may be problems. If certain aspects of risk information are ignored in the rating structure, they may be used for underwriting purposes. Applications by unwanted risk groups may be refused or "forgotten". By doing so, insurance companies can increase their profitability, while other companies will see their profits reduced.

This may also occur with "special character" companies: in almost every country there are companies (often mutuals) which sell insurance to agriculturers or to civil servants only or which operate in one specific area. These groups may turn out to consist of non-average risks.

To illustrate the effects of such a situation, let us assume that we are dealing with a two-company market. A risk factor $F$ has been discovered but it is not used in the tariffs. So both companies charge a level premium $E(X)$. Suppose that, due to the market mechanism described above, the insureds of company I are characterized by $F \in \mathscr{F}$ and those of company II by $F \notin \mathscr{F}$, where $\mathscr{F}$ is a subset of the possible outcomes of $F$. The expected risk carried by the companies now becomes:

$$
E(X \mid F \in \mathscr{F})-E(X) \text { for company I }
$$

and

$$
E(X \mid F \notin \mathscr{F})-E(X) \text { for company II }
$$

one of which, say for company I, may be positive.

This situation clearly leads to modifications in the profit and loss accounts of companies I and II. In a free market (but still assuming that $F$ remains removed from the tariffs), company I might consider adjusting its overall premium level.

\footnotetext{
* In reality, the difference has to be substantial before the effect becomes noticeable. Moreover, we simplify by considering the risk process only and by ignoring expenses, marketing and client service aspects.
} 
But this would mean that $F$ is effectively used as a rating factor, not on a company level but on the market level. Risks characterized by $F \in \mathscr{F}$ would be charged a higher premium (by company I) than risks characterized by $F \notin \mathscr{F}$ (insured with company II). Since this is what we were trying to avoid on grounds of social fairness, the situation is not very satisfactory and seems to call for another solution, especially if the premium differences are very large.

Another possibility is that the companies do not adjust their premiums to reflect the special character of the risks of their portfolio. The resulting positive value of the expected risk for company $I$ is a risk theoretical impossibility: the insurer will soon be ruined. In practice however, premiums contain loadings for security, expenses, profits etc.

This loading will now turn out to be lower than expected, because of the special risk selection represented by $F \in \mathscr{F}$. It may very well be possible that the company can still live and survive with this smaller loading. But its existence will have become subject to more risk and a larger safety buffer may therefore be required. See also DE Hullu (1984).

Let us return to fig. 2 . It illustrates that by deliberately ignoring some risk information, we find ourselves in situation $B$ instead of $A$. Solidarity between insureds $S_{p}+S_{u n}$ which was defined as the variance carried by the insurer, was thus increased. This increase of the variance is a second indication that the solvency margin of an insurer is to be increased when not all possible risk information is used in determining premiums. Such an increase would be based on risk variance grounds and therefore its nature is different from the one which reflects premium inadequacy due to risk selection $(F \in \mathscr{F})$.

The necessary provisions in situations $A$ and $B$ can thus be written as:

$$
\begin{aligned}
& R_{A}=R V_{A}+R S_{A} \\
& R_{B}=R V_{B}+R S_{B}
\end{aligned}
$$

where

$$
R V=k_{1} \sqrt{n} \sqrt{S_{p}+S_{u r}}
$$

is the variance part of the provision ( $n$ is the portfolio size), and

$$
R S=k_{2} n \sqrt{S_{u r}}
$$

is the risk selection part of the provision. We have

$$
\begin{aligned}
& R V_{A}<R V_{B} \\
& R S_{A}<R S_{B}
\end{aligned}
$$

and hence

$$
R_{A}<R_{B}
$$

It should further be noted that $R V$ expressed as a percentage of premium income, tends to zero when the size of the portfolio increases, This is not true for $R S$, which shows that the law of large numbers is not the whole story of insurance 
as is popularly believed. $R S$ will be zero when all risk information is reflected in premium differentiation. While much literature exists on the determination of the level of the variance part of the reserve, $R V$, it is hard to say anything general about the level of $R S$. We will simply mention two of the factors that can influence it:

- the explanatory power of the deliberately omitted risk factor $F$. The more $E(X \mid F=f)$ varies with $f$, the greater $S_{u n}$ and the greater will be the premium inadequacy resulting from adverse risk selection. The risk pattern in fig. $3 a$ is more dangerous than the one in fig. $3 b$.

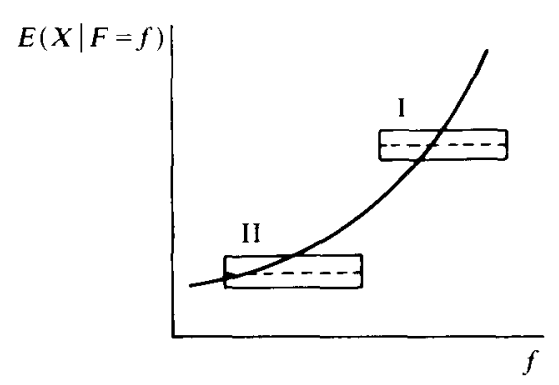

FIGURE 3a

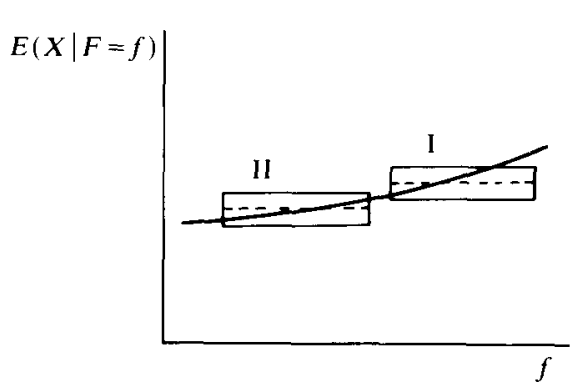

Figure 3b

- the possibility of the market to arrive at an effective risk selection. The most dangerous risk selection would result from a choice of $\mathscr{F}$ such that $E(X \mid F \in$ $\mathscr{F})-E(X \mid F \notin \mathscr{F})$ is maximized. In practice however, not all choices of $\mathscr{F}$ are possible. Social tolerance can be important in this respect. A health insurance company for instance, cannot openly say that it accepts insureds under age $\mathbf{3 0}$ only, without being highly controversial. So full risk selection (through age) would be impossible, but some degree of risk selection may be possible by means of carefully planned marketing campaigns. Such aspects are reflected in the value of $k_{2}$.

As we have seen, an extra security buffer may be necessary for protection against risk selection effects in a market where part of the risk information is not reflected in tariffs. This may however not be sufficient. The possibilities of fighting premium inadequacy by setting up extra provisions are limited. The difference between the net premium charged $(E(X))$ and the necessary net premium $(E(X \mid F \in \mathscr{F}))$ may be too large to be financed from the premium loading. In such cases another solution is necessary.

Since considerations of social fairness have led to the decision of non-differentiation of premiums with respect to $F$, this same sense of social fairness suggests a transfer of premium income from the companies characterized by $F \notin \mathscr{F}$ to those portfolios for which $F \in \mathscr{F}$ holds. Since $F$ is an observable risk factor, with known effect on the expected losses, the level for such a "fair transfer" can be computed. 
To realize such transfers in practice, a consensus between companies is necessary. This consensus can only be reached when there is full agreement on what is "socially fair". Public opinion and political pressure can prove to be major factors in the process of reaching a final agreement.

These principles have been applied in the Dutch health insurance market. "Age of the insured" is a highly significant risk factor but it is not used in tariffs. Deliberate and undeliberate risk selection by some companies have had a great impact on the profit and loss accounts of the Dutch companies. As a consequence of the free market mechanism premium levels have been adjusted, leading to highly differing premium levels from company to company. Thus age has factually returned as a rating factor. At present, proposals are being discussed to arrange transfers of premium income between companies, to cure the situation. The theoretically necessary safety provisions could then be reduced to a realistic level. Details can be found in the Appendix.

\section{CONCLUSION}

In this contribution we have tried to show that, depending on social circumstances, practical tariffs should not always reflect all the risk information available.

If the reduction of the relationship on a micro-level between risks insured and premiums charged is pushed to an extreme, the nature of the insurance industry will change profoundly, the end being a full socialization of insurance, with for instance income-related premiums. The different stages of such a process can be summarized as follows:

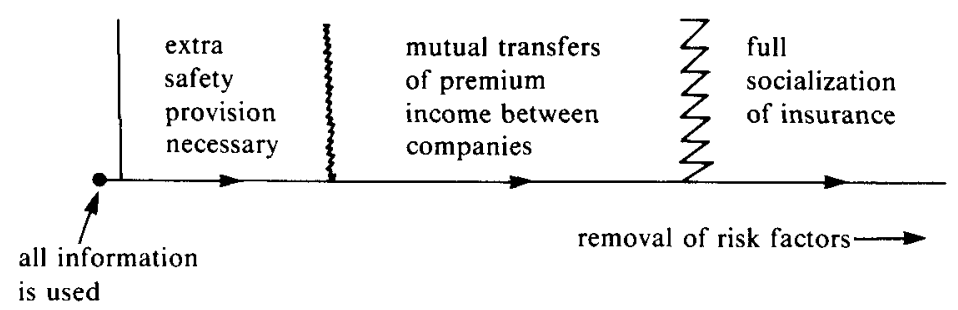

It is not our intention to plead for tariffs from which as many risk factors as possible have been removed. But in modern society, we should be aware of the fact that some aspects of the free market mechanism need to be adjusted. This also applies to insurance, and insurance companies need not feel threatened by these developments. The intention of this paper is therefore to take better noticeespecially in a quantitative sense-of the consequences of solidarity transfers. A better knowledge of these transfers may help the insurance industry to react adequately upon general social developments. If such a reaction should result in a reduced premium differentiation, the insurance industry will have to reach a consensus on whether to increase solvency requirements or to neutralize the effects of risk selection by mutual transfers of premium income. 


\section{APPENDIX}

\section{Health Insurance in the Netherlands}

In the Netherlands, $30 \%$ of the population obtains full health coverage from private insurance companies.

The most important risk factor $(F)$ for this type of risk is age of the insured. The expected loss for an individual of age $x$ is: $E(X \mid F=x)=S(x)$.

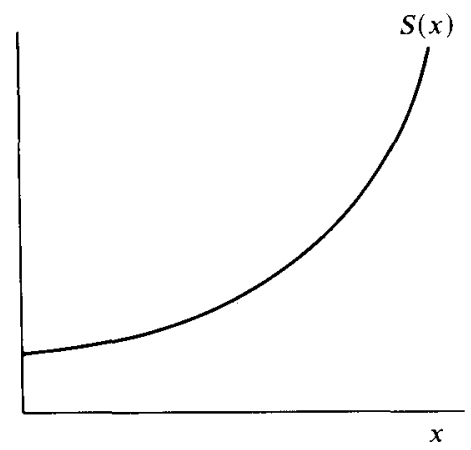

Clearly, age is a very significant risk factor. Premiums however, originally do not depend on age, but only on type of coverage and level of deductible. So if $N(x)$ is the number of insureds of age $x$ in the portfolio, the net premium applicable to all insureds is:

$$
P=\left(\sum_{x} N(x) S(x)\right) / \sum_{x} N(x) .
$$

An actuarial provision is not formed; the financing system used is pay-as-you-go.

This situation is a typical example of a rating structure where an important risk factor has been deliberately ignored, and the features described in the previous paragraph are observable in the market. Premiums differ widely from company to company, as a function of the age composition of the portfolio. Companies with a "young" portfolio have low premiums and therefore attract the largest number of new (mainly young) insureds. Companies with an "old" portfolio have high premiums, they will therefore not be able to attract enough new insureds, the portfolio therefore grows older and as a result they have to increase their premiums, possibly to an unacceptably high level. This feature is reinforced by the steepness of the $S(x)$-curve: $S(85)$ is about 7 times as high as $S(20)$. The situation in the market can therefore well be represented by fig. $3 a$ of the main text (for two companies). Due to the free market mechanism, age is de facto used as a rating factor.

An extra provision necessary to protect companies from possible premium inadequacies can be formed as follows.

Suppose there is a portfolio with a given age composition which attracts no more new insureds. The age composition in subsequent years is therefore fully determined by aging and mortality. 
If $p_{x}$ is the one-year survival probability of an $x$-year old insured, the expected number of insureds of age $x+t$ after $t$ years will be:

$$
N_{t}(x+t)=p_{x} \cdot p_{x+1} \cdots p_{x+t-1} N(x) \text {. }
$$

Suppose the premiums are to be kept constant at a level $P$, the discounted (interest $=100 i \%$ ) premium income for the company will be:

$$
D P=P \sum_{t}(1+i)^{-t} \sum_{x} N_{t}(x+t)
$$

while the discounted yearly claims total is:

$$
D C=\sum_{t}(1+i)^{-t} \sum_{x} N_{t}(x+t) S(x+t) .
$$

The difference $D C-D P$ could be considered as a theoretically necessary extra provision.

For the average Dutch portfolio this provision would be $440 \%$ of net premium income, an amount which is simply not available and is equal to the actuarial provision in a fully capitalized health insurance system without inflation.

To cope with this problem and with the problem of widely differing premium levels in the market (part of which is due to differing age compositions), the Dutch health insurance companies are in the process of deciding to share the costs of older insureds. Basically the proposal is as follows:

- for each insured of age $x>55$, the insurer receives $r[S(x)-S(55)]$ where $0 \leqslant r \leqslant 1$;

- for each insured of age $x<55$, the insurer pays $\lambda[S(55)-S(x)]$,

where $\lambda$ is determined in such a way that for the market as a whole and for fixed $r$, the balance of income and expenditure is zero.

The result of these transfers is a new (less steep) curve of expected losses:

$$
\begin{aligned}
S^{*}(x) & =(1-\lambda) S(x)+\lambda S(55) & & x<55 \\
& =S(55) & & x=55 \\
& =(1-r) S(x)+r S(55) & & x>55 .
\end{aligned}
$$

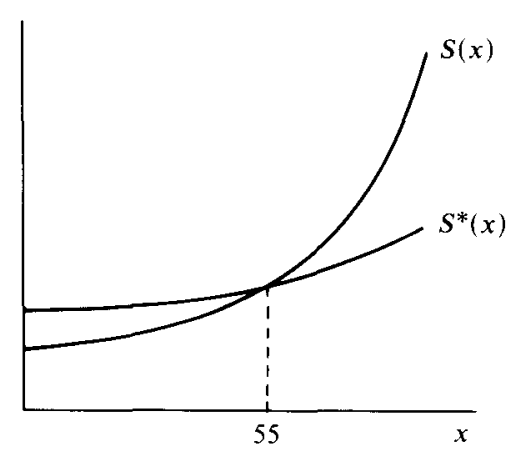


Due to the reduction of the slope of the $S$-curve, premium differences in the market will decrease, so that the resulting situation might be represented by figure $3 b$ of the main text.

If we compute the level of the necessary safety provision in a similar way as above, but with $S(x)$ replaced by $S^{*}(x)$, we find, for the values of $r$ and $\lambda$ suggested by the Dutch insurers, a provision of $20 \%$ of premium income, which is more in line with the financial position of the Dutch health insurance industry than the previous $440 \%$.

This is a mixed solution. The $S^{*}$-curve is not completely horizontal. The factor age continues to be of importance, also because the premium transfers relate only to a specific part of the total health insurance coverage. An extra provision $(20 \%)$ thus remains necessary. Premium differences due to differences in age composition are strongly reduced. Solidarity between younger and older insureds is thus secured through an agreement between insurance companies which does not interfere with normal, healthy competition.

\section{REFERENCES}

BICHSEL, F. (1983) Versicherungsprämien und optimales Verhalten von Konsumenten und Produzenten gegenüber Risiken. Mitteilungen der Vereinigung schweizerischer Versicherungsmathematiker, 1983, 105-113

Eeghen, J, van, Greup, E. K. and Nijssen, J. A. (1983) Rate Making, Surveys of Actuarial Studies No 2. Nationale-Nederlanden N. V., Rotterdam.

Hullu, A. DE (1984) A Management Oriented Approach to Solvency. Transactions 22nd International Congress of Actuaries, Sydney, Volume 3, 21-29.

WrT, G. W. DE (1982) Premium Calculation in Theory and Practice. General Insurance Bulletin (Australia), nr. 34 (June); also published in Bulletin de l'Association Royale des Actuaires Belges, nr. 76. 